\title{
Desempenho de pintos de corte alimentados com rações contendo milho pré-gelatinizado
}

\author{
José Henrique Stringhini ${ }^{1,5}$, Denise Alencar Santos ${ }^{2,5}$, Alexandre Barbosa de Brito ${ }^{3}$, Romão da \\ Cunha Nunes $^{1}$, Luciana Moura Rufino ${ }^{2}$, Bruno Moreira dos Santos ${ }^{4,5}$
}

\author{
${ }^{1}$ Departamento de Produção Animal, Escola de Veterinária, Universidade Federal de Goiás. \\ 2 Pós-Graduação em Ciência Animal - UFG. \\ 3 Polinutri Alimentos, Rua Américo Vespúcio, 99, Jardim Platina, Osasco, SP, CEP: 06273-070. \\ ${ }^{4}$ Graduação em Medicina Veterinária - UFG. \\ ${ }^{5}$ Bolsista do CNPq.
}

RESUMO - Foram conduzidos três experimentos para avaliar o valor nutricional do milho pré-gelatinizado para frangos de corte de 1 a 21 dias de idade. No primeiro experimento, avaliou-se o metabolismo do milho pré-gelatinizado, do amido e do gérmen de milho pelo método da colheita total de excretas no período de 4 a 7 dias de idade para determinação dos valores de energia metabolizável aparente e aparente corrigida, que foram de 3.370, 3.379,7, 3.259,1 kcal/kg de EMA e 3.299,8, 3.369,7 e 3.051,6 kcal/kg de EMAn, para o milho pré-gelatinizado, o amido de milho e o gérmen de milho integral, respectivamente. No segundo e terceiro experimentos, utilizaram-se 200 pintos alimentados com rações pré-iniciais (fase de 1 a 7 dias de idade) e iniciais com 0, 20, 40 ou 60\% de milho pré-gelatinizado em substituição ao milho-grão. O desempenho dos frangos no período de 1 a 7 dias não foi afetado pelos níveis de milho pré-gelatinizado na ração. Houve nesse período efeito quadrático sobre o coeficiente de digestibilidade da matéria seca (ponto de mínima de 28,6\%) e do nitrogênio (ponto de mínima de 31,7\%) e efeito linear negativo sobre o coeficiente de digestibilidade do extrato etéreo. No período de 8 a 21 dias de idade, para os níveis de milho pré-gelatinizado, houve efeito linear negativo sobre o peso final, o ganho de peso e o consumo de ração e efeito quadrático sobre a conversão alimentar (ponto de máxima de 34,3\%). Os coeficientes de digestibilidade da matéria seca, do nitrogênio e do extrato etéreo indicaram efeito linear positivo dos níveis de substituição do milho-grão moído pelo pré-gelatinizado. O milho pré-gelatinizado é uma boa alternativa para alimentação de pintos de corte na fase pré-inicial, porém, apesar do melhor aproveitamento nutricional da ração, piora o desempenho na fase de 8 a 21 dias de idade.

Palavras-chave: conversão alimentar, digestibilidade, energia metabolizável, ganho de peso, valor nutricional

\section{Performance of broiler chicks fed pre-gelatinized corn in pre-starter and starter feed}

\begin{abstract}
Three experiments were carried out to evaluate the performance and nutritional value of the extruded corn for broilers from one to 21 days of age. In the first experiment, the metabolism of pre-gelatinized corn, corn starch and corn germ meal was assessed by the total excreta collection method from 4 to 7 days of age and values of apparent (AME) and corrected metabolizable energy (CAME) and the results were, respectively: 3370, 3379.7, 3259.1 kcal/kg de AME and 3299.8, 3369.7, $3051.6 \mathrm{kcal} / \mathrm{kg}$ for CAME. The inclusion level of pre-gelatinized corn was evaluated in pre-starter (1 to 7 days of age - Experiment 2) and starter (8 to 21 days of age - Experiment 3) broiler rations. Broiler performance from one to seven days of age was not affected by pre-gelatinized corn in the feed. A quadratic effect for the dry matter digestibility coefficient (minimum point of $28.6 \%$ inclusion) and nitrogen (minimum point of $31.7 \%$ inclusion) and negative linear negative on the ether extract digestibility coefficient. From 8 to 21 days of age, broiler performance was affected linearly and negatively for final weight, weight gain and feed intake and quadratic for feed-to-gain ratio (maximum point of 34.3\% inclusion). For the dry matter, nitrogen and ether extract digestibility coefficients, there was a positive linear effect for pre-gelatinized corn included in substitution of corn. Pre-gelatinized corn was a good alternative for pre-starter ration, but, in spite of the better digestibility coefficient results, performance got worse as pre-gelatinized corn increased in diets from 8 to 21 days of age. Pre-gelatinized corn was a good alternative as energetic ingredient for first week chick feed, but, in the starter phase it did not promote good performance despite the good digestibility indexes obtained.
\end{abstract}

Key Words: digestibility, feed-to-gain ratio, metabolizable energy, nutritional value, weight gain 


\section{Introdução}

O milho é a principal fonte de energia na alimentação das aves e fornece 22 a 35\% da proteína bruta total; sua maior limitação é o baixo conteúdo de lisina e triptofano (Dale, 1994; Lima, 2001; Rodrigues et al., 2001, Oliveira et al., 2004; Fasuyi, 2005).

O milho apresenta grande diversidade de utilização na alimentação humana e animal, com mais de 500 derivados nas indústrias química, alimentícia, química mecânica, bebidas, indústria de rações e outras (Larbier \& Leclerq, 1994; Lima, 2001). Os produtos do milho podem ser obtidos no processo de industrialização, tanto por via seca quanto por via úmida. Os principais ingredientes obtidos do milho por via seca (Lima, 2001) são: gérmen de milho integral ou desengordurado; óleo de gérmen de milho; canjica; farelo de milho degerminado e gritz. Na via úmida, podem ser citados como ingredientes: farelo de gérmen de milho e farelo de glúten de milho.

O amido dos cereais se apresenta na forma de grânulos formados por amilose (22\% a $28 \%$ ) e amilopectina (72\% a $78 \%$ ), cujo interior do grânulo é composto de regiões cristalinas e amorfas alternadas, formando um complexo altamente organizado. A região cristalina ou micelar é composta principalmente por amilopectina e é resistente à entrada de água e à ação das enzimas (Joy et al., 1997).

A extrusão é empregada para obtenção de amidos modificados, solúveis e com elevada capacidade de retenção de água, pela gelatinização e dextrinização, o que permite melhor digestão e absorção dos nutrientes (Moreira et al., 1994). O amido processado comercialmente é composto de grãos ou grânulos de amido insolúveis que absorvem pequena quantidade de líquido em água fria. $\mathrm{O}$ amido entra no processo de gelatinização entre 60 e $70^{\circ} \mathrm{C}$ de acordo com a fonte e o tipo de grânulo (Food Oregon State, 2006).

O milho pré-gelatinizado é obtido a partir de grãos sadios de milho (Zea mays L.) degerminados, moídos e submetidos às operações de pré-gelatinização por extrusão e posteriormente seco, moído e classificado. A retenção máxima em peneiras ABNT-40 é de $20 \%$, o que representa $80 \%$ de partículas menores que $0,42 \mathrm{~mm}$ e com características organolépticas marcantes, com aspecto de um produto fino, uniforme, de cor amarela, sabor e aroma suave característicos do milho (Moreira et al., 2001). Na extrusão, ocorre mudança física do amido, ocasionando sua gelatinização. Inicialmente, a água aquecida rompe a cristalinidade da amilose e desfaz sua estrutura ordenada. Os grânulos de amido incham e aumentam de volume. A amilose começa a se expandir, os grânulos se rompem e mais moléculas de água se unem aos radicais hidroxílicos expostos na cadeia de amido, resultando em uma estrutura de gel coloidal com a amilose. As moléculas de amido se recombinam, ligando-se a outros nutrientes, formando estrutura porosa, relativamente estável, e que serve para absorver gordura e umidade (Jorge Neto, 1992, 1993).

Na primeira semana, ocorrem eventos fisiológicos digestivos peculiares, pois as aves não estão plenamente adaptadas à ingestão de carboidratos e lipídios (Castro, 1996; Toledo et al., 2001) e acredita-se que o milho processado pode se constituir boa opção para as rações nessa idade. Neste estudo, objetivou-se determinar os valores de energia metabolizável de produtos do processamento do milho (milho pré-gelatinizado, amido e gérmen de milho integral GMI) para pintos de corte. Avaliou-se também o desempenho de pintos de corte alimentados com rações contendo níveis crescentes de milho pré-gelatinizado nas fases de 1 a 7 dias e de 8 a 21 dias de idade.

\section{Material e Métodos}

Foram conduzidos dois experimentos no aviário experimental do Departamento de Produção Animal da Escola de Veterinária da Universidade Federal de Goiás. No primeiro experimento, foram utilizados 128 pintos de corte da marca comercial Cobb, de ambos os sexos, distribuídos entre quatro dietas: dieta-referência, à base de milho e soja, formulada para conter $3.000 \mathrm{kcal} / \mathrm{kg}$ de EMAn e 20,88\% de PB; dieta-referência com $40 \%$ de milho prégelatinizado; dieta-referência com $40 \%$ de amido de milho; dieta-referência com $40 \%$ de milho pré-gelatinizado. O período experimental foi de 14 a 21 dias de idade das aves. O método de colheita total de excretas foi utilizado e os alimentos e as excretas, depois de colhidos, foram pesados e processados para análises laboratoriais e determinação dos teores de matéria seca $\left(60\right.$ e $\left.105^{\circ} \mathrm{C}\right)$, nitrogênio, pelo método de Kjeldahl, e extrato etéreo, pelo método de Goldfisch, segundo as marchas analíticas descritas por Silva \& Queiroz (2002).

O delineamento adotado foi o inteiramente casualizado com quatro dietas e quatro repetições de oito aves adotando-se o teste de Tukey (5\%) para comparação das médias. A análise estatística foi realizada pelo programa SAEG(UFV, 2000).

No segundo experimento, avaliou-se o desempenho de pintos de corte de 1 a 7 dias de idade alimentados com rações com diversos níveis de milho pré-gelatinizado $(0,20$, 40 e $60 \%)$. O experimento foi realizado de 5 de agosto a 10 de setembro de 2005 utilizando-se 200 pintos de corte Cobb, machos com 1 dia de vida, divididos em grupos de dez aves por unidade experimental. 
As aves foram alojadas em baterias de aço galvanizado, cada uma com cinco andares, instaladas em galpão de alvenaria com 12,96 $\mathrm{m} \times 2,96 \mathrm{~m}\left(38,36 \mathrm{~m}^{2}\right)$ de dimensões internas, cumeeira com orientação leste-oeste, pé-direito de 2,32 m, sem lanternim, coberto com telhas de barro. Todo o galpão era rodeado por mureta de concreto com 0,46 m e tela de arame até o início do telhado, com altura de $1,70 \mathrm{~m}$, protegido por cortina de plástico externa trançada azul e sistema de catracas para movimentação. $\mathrm{O}$ aquecimento foi realizado com lâmpadas incandescentes de 60 W. A iluminação foi constante, com 12 horas de iluminação natural e 12 horas de iluminação artificial por dia. A iluminação artificial foi feita por meio de lâmpadas incandescentes de $100 \mathrm{~W}$ espalhadas pelo galpão. O aquecimento interno do galpão foi monitorado diariamente e associado ao manejo das cortinas para manter a temperatura interna adequada às aves.

Os comedouros e bebedouros eram do tipo calha, e o manejo diário incluiu a limpeza dos bebedouros, com troca de água pela manhã e à tarde e fornecimento de ração nos comedouros duas vezes ao dia. Tanto os pintos quanto as dietas foram pesados no $1 \underline{0}$ e $7 \underline{0}$ dia de idade e esses dados serviram como base para o cálculo do ganho de peso, do consumo de ração e do índice de conversão alimentar. Foi avaliado também o desempenho até os 21 dias de idade.

As dietas foram formuladas com quatro níveis de substituição do milho-grão por milho pré-gelatinizado (0; 20; 40 e 60\%) para atender às recomendações nutricionais e a composição dos alimentos proposta por Rostagno et al. (2000) (Tabela 1).

Os pintos foram alimentados com as rações experimentais do $1^{\underline{0}}$ ao $7 \underline{0}$ dia de idade: os primeiros dois dias ( $1^{\circ} \underline{0}$ e $2^{\underline{0}}$ dia $)$ foram de adaptação às dietas com milho pré-gelatinizado e os outros cinco dias ( $3^{\circ}$ ao $7 \underline{0}$ dia), de colheita de excretas, conforme metodologia descrita por Café (1993).

A colheita de excretas foi realizada pelo método da coleta total descrito por Albino (1991), duas vezes ao dia, durante todo o período experimental, e acondicionadas em sacos plásticos identificados e posteriormente congeladas. O material colhido foi misturado e homogeneizado.

A determinação dos coeficientes de digestibilidade da matéria seca, do nitrogênio e do extrato etéreo foi conduzida segundo a metodologia descrita por Matterson et al. (1965). Com base nos resultados laboratoriais obtidos, foram calculados os valores do balanço de nitrogênio utilizando-se a equação: $\mathrm{Bn}=(\mathrm{N}$ ing $-\mathrm{N}$ exc $) / \mathrm{N}$ ing., de modo que $\mathrm{BN}$ é igual ao balanço de nitrogênio, $\mathrm{N}$ ing. é o nitrogênio ingerido e $\mathrm{N}$ exc. é o nitrogênio excretado.

A análise estatística foi realizada seguindo o esquema da ANOVA para um delineamento inteiramente casualizado, com quatro tratamentos, cada um com cinco repetições. Foi utilizado o programa SAEG (UFV, 2000), adotada a análise de variância e aplicada a análise de regressão polinomial para os níveis de milho pré-gelatinizado testados (5\% probabilidade).

No terceiro experimento, avaliou-se o desempenho de pintos de corte alimentados com rações com diferentes níveis de milho pré-gelatinizado na fase de 8 a 21 dias de idade. O experimento foi realizado de 20 de dezembro de 2005 a 20 de janeiro de 2006, com 280 pintos de corte Cobb, machos com 1 dia de vida, no mesmo sistema de manejo e controle de temperatura adotado no segundo experimento.

Os trechos grifados a seguir são desnecessários, uma vez que o manejo foi o mesmo do experimento anterior.

Utilizaram-se três baterias de aço galvanizado, cada uma com cinco andares e divisões. Essas baterias foram instaladas em galpão de alvenaria com 12,96 m × 2,96 m $\left(38,36 \mathrm{~m}^{2}\right)$ de dimensões internas, cumeeira com orientação leste-oeste, pé-direito de 2,32 m, sem lanternim, coberto com telhas de barro. Todo o galpão é rodeado por uma mureta de concreto com 0,46 m e tela de arame até o início do telhado, com uma altura de $1,70 \mathrm{~m}$, e protegido na parte

Tabela 1 - Composição das dietas experimentais pré-iniciais fornecidas na fase de 1 a 7 dias de idade

\begin{tabular}{|c|c|c|c|c|}
\hline \multirow[b]{2}{*}{ Ingrediente (\%) } & \multicolumn{4}{|c|}{ Nível de milho pré-gelatinizado (\%) } \\
\hline & 0 & 20 & 40 & 60 \\
\hline Milho & 57,4 & 45,9 & 34,4 & 22,9 \\
\hline Milho pré-gelatinizado & - & 10,8 & 21,6 & 32,4 \\
\hline Farelo de soja & 37,2 & 37,8 & 38,5 & 39,2 \\
\hline Óleo soja & 1,64 & 1,68 & 1,71 & 1,75 \\
\hline Fosfato bicálcico & 1,81 & 1,81 & 1,81 & 1,80 \\
\hline Calcário & 0,79 & 0,78 & 0,78 & 0,78 \\
\hline Sal comum & 0,42 & 0,42 & 0,42 & 0,42 \\
\hline DL -metionina & 0,189 & 0,185 & 0,181 & 0,177 \\
\hline L-lisina HCL & 0,174 & 0,156 & 0,139 & 0,121 \\
\hline $\begin{array}{l}\text { Suplemento mineral } \\
\text { e vitamínico }{ }^{1}\end{array}$ & 0,4 & 0,4 & 0,4 & 0,4 \\
\hline Total & 100,0 & 100,0 & 100,0 & 100,0 \\
\hline \multicolumn{5}{|l|}{ Composição nutricional ${ }^{2}$} \\
\hline Proteína bruta (\%) & 19,900 & 19,900 & 19,900 & 19,900 \\
\hline $\begin{array}{l}\text { Energia metabolizável } \\
\text { (kcal/kg) }\end{array}$ & 3.000 & 3.000 & 3.000 & 3.000 \\
\hline Fósforo total (\%) & 0,645 & 0,645 & 0,645 & 0,645 \\
\hline Fósforo disponível (\%) & 0,421 & 0,421 & 0,421 & 0,421 \\
\hline Cálcio (\%) & 0,839 & 0,839 & 0,839 & 0,839 \\
\hline Sódio (\%) & 0,203 & 0,203 & 0,203 & 0,203 \\
\hline L-lisina $(\%)$ & 1,126 & 1,126 & 1,126 & 1,126 \\
\hline DL-metionina (\%) & 0,439 & 0,439 & 0,439 & 0,439 \\
\hline
\end{tabular}

${ }^{1}$ Premix inicial (Suplemento vitamínico): vitamina A - 8.000,000 UI; vitamina D3 - 2.000,000 UI; vitamina E - 15.000 UI; vitamina K - 1.800 mg; vitamina B1 $1.800 \mathrm{mg}$; vitamina B2 - $6.000 \mathrm{mg}$; vitamina B6 - $2.800 \mathrm{mg}$; vitamina B12 $12.000 \mathrm{mg}$; niacina - $40.000 \mathrm{mg}$; ácido fólico - $1.00 \mathrm{mg}$; ácido pantotênico $15.000 \mathrm{mg}$, biotina - $60 \mathrm{mg}$; selênio - $300 \mathrm{mg}$; antioxidante - $30 \mathrm{~g}$.

2 Valores calculados com base na composição química dos alimentos, proposta pela tabela de Rostagno et al. (2000).

Suplemento mineral: manganês - 150.000 mg; zinco - 100.00 mg; ferro - 100.000 mg; cobre - $16.000 \mathrm{mg}$; iodo $-1.500 \mathrm{mg}$. 
externa por uma cortina de plástico trançada azul e um sistema de catracas para sua movimentação.

$\mathrm{O}$ manejo anterior à chegada dos pintos consistiu de limpeza e desinfecção das instalações (telhas, piso, área externa, equipamentos), respeitando o tempo de vazio sanitário, com pulverização de desinfetantes nas instalações e nos equipamentos.

$\mathrm{O}$ aquecimento interno de cada andar das baterias foi realizado pela instalação de lâmpadas incandescentes de 60 W. A iluminação foi constante, com 12 horas de iluminação natural e 12 horas de iluminação artificial por dia. A iluminação artificial foi feita por meio de lâmpadas incandescentes de $100 \mathrm{~W}$ espalhadas pelo galpão. O aquecimento interno do galpão foi monitorado diariamente e associado ao manejo das cortinas para manter a temperatura interna adequada às aves. Os comedouros e bebedouros foram do tipo calha e o manejo diário incluiu a limpeza dos bebedouros com troca de água pela manhã e à tarde e fornecimento de ração nos comedouros duas vezes ao dia.

Os pintos foram alimentados com dieta experimental do $8^{\circ}$ ao $21^{\circ}$ dia de idade: nove dias de adaptação às dietas com milho pré-gelatinizado e cinco dias de colheita de excretas, conforme metodologia descrita por Café (1993). A colheita de excretas obedeceu ao método da coleta total descrito por Albino (1991) e foi realizada duas vezes ao dia durante o período experimental.

As dietas experimentais (Tabela 2) foram formuladas com quatro níveis ( 0 ; 20; 40 e 60\%) de substituição do milhogrão por milho pré-gelatinizado, de modo a atenderem às recomendações nutricionais, considerando a composição dos alimentos proposta por Rostagno et al. (2000).

Na condução do experimento, foram avaliados os pesos dos pintos de corte e das dietas fornecidas ao $8^{\circ}$, $13^{\circ}$, $17 \underline{0}$ e $21^{0}$ dias de idade, adotando-se os pesos dos animais mortos, e calculados o ganho de peso, o consumo de ração e o índice de conversão alimentar.

A determinação da matéria seca e do nitrogênio foi conduzida de acordo com metodologia descrita por Matterson et al. (1965). A partir dos resultados laboratoriais foram calculados os valores do balanço de nitrogênio (BN) com a equação: $B N=($ Ning-Nexc)/Ning., em que Ning. é o nitrogênio ingerido e Nexc. o nitrogênio excretado.

O experimento foi realizado em delineamento inteiramente casualizado, com quatro níveis de milho prégelatinizado na dieta, cada um com 7 repetições de 10 pintos de corte, totalizando 28 unidades experimentais.

As análises estatísticas para esse experimento foram realizadas utilizando-se o programa SAEG (UFV, 2000), com análise de variância e análise de regressão até o terceiro grau (5\% probabilidade).
Tabela 2 - Composição das rações fornecidas na fase inicial (8 a 21 dias)

\begin{tabular}{|c|c|c|c|c|}
\hline \multirow[b]{2}{*}{ Ingrediente (\%) } & \multicolumn{4}{|c|}{ Nível de milho pré-gelatinizado (\%) } \\
\hline & 0 & 20 & 40 & 60 \\
\hline Milho & 60,202 & 48,162 & 36,121 & 24,081 \\
\hline Milho pré-gelatinizado & - & 11,348 & 22,696 & 34,044 \\
\hline Farelo de soja (45\%) & 34,450 & 35,120 & 35,790 & 36,460 \\
\hline Óleo de soja & 1,934 & 1,965 & 1,996 & 2,028 \\
\hline Fosfato bicálcico & 1,680 & 1,676 & 1,672 & 1,668 \\
\hline Calcário & 0,757 & 0,754 & 0,750 & 0,747 \\
\hline Sal & 0,402 & 0,404 & 0,405 & 0,407 \\
\hline Metionina & 0,126 & 0,133 & 0,140 & 0,146 \\
\hline Lisina & 0,049 & 0,039 & 0,029 & 0,020 \\
\hline Núcleo $^{1}$ & 0,400 & 0,400 & 0,400 & 0,400 \\
\hline Total & 100,00 & 100,00 & 100,00 & 100,00 \\
\hline
\end{tabular}

Composição nutricional ${ }^{2}$

\begin{tabular}{|c|c|c|c|c|}
\hline Proteína bruta (\%) & 20,980 & 20,980 & 20,980 & 20,980 \\
\hline $\begin{array}{l}\text { Energia metabolizável } \\
(\mathrm{kcal} / \mathrm{kg})\end{array}$ & 2.950 & 2.950 & 2.950 & 2.950 \\
\hline Fósforo total (\%) & 0,677 & 0,677 & 0,677 & 0,677 \\
\hline Fósforo disponível (\%) & 0,448 & 0,448 & 0,448 & 0,448 \\
\hline Cálcio (\%) & 0,891 & 0,891 & 0,891 & 0,891 \\
\hline Sódio (\%) & 0,211 & 0,211 & 0,211 & 0,211 \\
\hline L-lisina (\%) & 1,316 & 1,316 & 1,316 & 1,316 \\
\hline DL-metionina (\%) & 0,513 & 0,513 & 0,513 & 0,513 \\
\hline
\end{tabular}

${ }^{1}$ Premix inicial (Suplemento vitamínico): vitamina A - 8.000,000 UI; vitamina D3 - 2.000,000 UI; vitamina E - 15.000 UI; vitamina K - 1.800 mg; vitamina B1 $1.800 \mathrm{mg}$; vitamina B2 - $6.000 \mathrm{mg}$; vitamina B6 - $2.800 \mathrm{mg}$; vitamina B12 $12.000 \mathrm{mg}$; niacina - $40.000 \mathrm{mg}$; ácido fólico - $1.00 \mathrm{mg}$; ácido pantotênico $15.000 \mathrm{mg}$; biotina - $60 \mathrm{mg}$; selênio - $300 \mathrm{mg}$; antioxidante - $30 \mathrm{~g}$.

2 Valores calculados com base na composição química dos alimentos, proposta pela tabela de Rostagno et al. (2000).

\section{Resultados e Discussão}

No primeiro experimento, em que foi realizada a determinação do conteúdo de energia metabolizável aparente do milho pré-gelatinizado, do amido de milho e do gérmen de milho, o amido de milho disponível para alimentação animal apresentou maiores valores de energia metabolizável, tanto aparente como corrigida pelo balanço de nitrogênio, porém esses valores foram significativamente diferentes quando expressos na matéria seca (Tabela 3). Na avaliação desses dados de energia metabolizável, observaram-se valores inferiores aos descritos por Freitas et al. (2005) para pintos de corte de 1 a 8 dias de idade para o milho processado (3 minutos a vácuo, retirada do oxigênio, e aquecimento de $63 \mathrm{a} 107^{\circ} \mathrm{C}$, e vapor direto por 8 a 12 minutos) e o não-processado (3.537 versus $3.411 \mathrm{kcal} \mathrm{EMAn/kg).}$ Plavnik \& Sklan (1995) deteriminaram incrementos de 1,5 para energia metabolizável aparente (EMA) e de 3,5\% para energia metabolizável aparente corrigida pelo balanço de nitrogênio (EMAn).

Para esse mesmo alimento, constataram-se maiores valores de digestibilidade da matéria seca, porém o gérmen de milho apresentou maior digestibilidade da proteína 
Tabela 3 - Composição de proteína e de matéria seca e valores energéticos determinados nas amostras experimentais

\begin{tabular}{|c|c|c|c|c|c|c|}
\hline \multirow[t]{2}{*}{ Ingrediente } & \multirow[t]{2}{*}{$\begin{array}{l}\text { Matéria } \\
\text { seca }(\%)\end{array}$} & \multirow[t]{2}{*}{$\begin{array}{l}\text { Proteína } \\
\text { bruta (\%) }\end{array}$} & \multicolumn{2}{|c|}{$\begin{array}{l}\text { Energia metabolizável } \\
\text { aparente }\end{array}$} & \multicolumn{2}{|c|}{$\begin{array}{l}\text { Energia metabolizável aparente } \\
\text { corrigida pelo balanço de nitrogêni }\end{array}$} \\
\hline & & & Matéria natural & Matéria seca & Matéria natural & Matéria seca \\
\hline Milho pré-gelatinizado & 90,62 & 7,50 & 3370,0 & 3718,8 & 3299,8ab & $3641,3 \mathrm{ab}$ \\
\hline Amido de milho & 90,16 & 1,10 & 3379,7 & 3748,5 & $3369,7 a$ & $3737,5 a$ \\
\hline Gérmen de milho & 90,09 & 9,94 & 3259,1 & 3617,6 & $3051,6 b$ & $3387,2 b$ \\
\hline Coeficiente de variação (\%) & & & 4,81 & 4,81 & 4,57 & 4,57 \\
\hline
\end{tabular}

${ }^{a b}$ Médias seguidas de letras distintas na coluna indicam diferença Tukey (5\% de probabilidade).

(Tabela 4). Todos os alimentos caracterizaram-se como concentrados energéticos pelos valores de energia apresentados. Freitas et al. (2005) determinaram valores de coeficiente de digestibilidade da matéria seca de 82,03 e de $81,36 \%$, coeficiente de digestibilidade da proteína bruta de 63,87 e $62,57 \%$, respectivamente, para os milhos processado e não-processado, valores semelhantes aos obtidos neste estudo.

No segundo experimento, no qual o milho pré-gelatinizado foi avaliado no período de 1 a 7 dias de idade, não se verificou efeito do processamento do milho no desempenho dos animais (Tabela 5). Esses resultados diferem dos encontrados por Brito et al. (2005), que observaram efeito da inclusão de gérmen integral de milho na dieta. Penz Jr. \& Vieira (1998) afirmaram que, na primeira semana, a anatomia e fisiologia do aparelho digestório de pintos de corte difere da observada em aves com mais idade, por isso, suas necessidades nutricionais são diferentes, pelas dificuldades em digerir e absorver nutrientes. Freitas et al. (2005), no entanto, constataram pior desempenho, com maior consumo e pior conversão alimentar na fase pré-inicial.

O consumo de ração e a conversão alimentar não apresentaram diferença estatística entre os níveis de milho pré-gelatinizado testados, uma vez que a média de consumo diário foi de 7,86 g. Os resultados obtidos estão de acordo com os descritos por Brito et al. (2005), que não constataram efeito significativo no consumo de ração e na conversão

Tabela 4 - Coeficientes de digestibilidade da matéria seca e da proteína e balanço de nitrogênio determinados

\begin{tabular}{lccc}
\hline & \multicolumn{2}{c}{$\begin{array}{c}\text { Coeficiente de } \\
\text { digestibilidade }\end{array}$} & $\begin{array}{c}\text { Balanço de } \\
\text { nitrogênio(g) }\end{array}$ \\
\cline { 2 - 3 } Ingrediente & $\begin{array}{c}\text { Matéria } \\
\text { seca (\%) }\end{array}$ & $\begin{array}{c}\text { Proteína } \\
\text { bruta (\%) }\end{array}$ & \\
\hline Ração referência & $76,44 \mathrm{~b}$ & $65,32 \mathrm{ab}$ & $4,99 \mathrm{~b}$ \\
Pré-gelatinizado & $79,07 \mathrm{~b}$ & $66,52 \mathrm{ab}$ & $3,92 \mathrm{bc}$ \\
Amido & $82,24 \mathrm{a}$ & $64,32 \mathrm{~b}$ & $2,83 \mathrm{c}$ \\
GMI & $76,16 \mathrm{~b}$ & $72,16 \mathrm{a}$ & $6,47 \mathrm{a}$ \\
CV (\%) & 2,87 & 5,41 & 11,71 \\
\hline
\end{tabular}

ab Médias seguidas de letras distintas na coluna indicam diferença Tukey (5\% de probabilidade). alimentar ao utilizarem gérmen integral de milho nas rações. Todavia, diferem dos encontrados por Freitas et al. (2005), que observaram piores consumo e conversão alimentar com o milho processado e atribuíram esses valores aos efeitos do óleo acrescentado às dietas, que permitiram o efeito extracalórico que melhorou o desempenho.

O coeficiente de digestibilidade (Tabela 6) indicou efeito quadrático $(\mathrm{P}<0,05)$ para matéria seca e ponto de mínima com 28,7\% de substituição do milho pelo milho prégelatinizado. Os teores de nitrogênio e extrato etéreo, no entanto, não diferiram $(\mathrm{P}>0,05)$ entre as rações.

No terceiro experimento, no qual foi avaliado o desempenho de pintos de corte alimentados com níveis de milho pré-gelatinizado no período de 8 a 21 dias de idade (Tabela 5), observou-se efeito linear negativo $(\mathrm{P}<0,05)$ dos níveis de milho pré-gelatinizado sobre o peso aos 21 dias de idade, o que significa que o aumento do nível de substituição do milho grão pelo milho pré-gelatinizado piorou o desempenho das aves. Fisher et al. (2002) observaram efeito da adição ou não de enzimas na dieta sobre o peso médio no período de 1 a 35 dias. Freitas et al. (2005) verificaram que a utilização de milho processado piorou a conversão alimentar.

Nesse período experimental, de 8 a 21 dias de idade, observou-se efeito linear negativo do processamento do amido no ganho de peso de pintos de corte. Os resultados estão de acordo com os encontrados por Brito et al. (2005), que observaram efeito significativo do nível de gérmen integral de milho na dieta de pintos de corte.

O consumo de ração não diferiu entre os níveis de milho pré-gelatinizado e a média diária foi de 57,20 g. Penz Jr. \& Vieira (1998) afirmaram que as alterações do aparelho digestório dos frangos de corte nos primeiros dias de vida são marcantes e que essas rápidas alterações do aparelho digestório possibilitam aumento de consumo de ração e altera a digestibilidade dos nutrientes. Essa observação comprova que, nesta fase estudada, a granulometria da ração não influenciou no consumo de ração.

Os resultados para conversão alimentar comprovaram efeito quadrático $(\mathrm{P}<0,05)$. O ponto de máxima da curva, obtido derivando-se a equação de regressão, foi de $34,22 \%$ 
Tabela 5 - Desempenho de pintos de corte de 1 a 7 dias de idade alimentados com rações contendo milho pré-gelatinizado

\begin{tabular}{|c|c|c|c|c|c|c|}
\hline & \multicolumn{4}{|c|}{ Nível de substituição (\%) } & CV (\%) & $\mathrm{P}$ \\
\hline \multicolumn{7}{|c|}{1 a 7 dias de idade } \\
\hline Peso final (g) & 156,23 & 157,36 & 143,77 & 141,12 & 8,82 & $>0,05$ \\
\hline Ganho de peso (g) & 108,05 & 108,88 & 95,62 & 93,98 & 12,93 & $>0,05$ \\
\hline Consumo de ração (g) & 112,98 & 122,42 & 104,42 & 100,86 & 11,52 & $>0,05$ \\
\hline Peso final, (g)* & 864,71 & 814,75 & 785,32 & 766,98 & 5,07 & $<0,001$ \\
\hline Ganho de Peso (g)** & 664,12 & 617,00 & 591,48 & 571,75 & 7,31 & 0,004 \\
\hline Consumo de ração (g)*** & 803,60 & 849,04 & 808,57 & 742,02 & 8,65 & $>0,05$ \\
\hline Conversão alimentar $(\mathrm{kg} / \mathrm{kg})^{* * *}$ & 1,212 & 1,375 & 1,369 & 1,298 & 6,77 & 0,006 \\
\hline
\end{tabular}

$\mathrm{P} *(=0,001), \mathrm{Y}=611,1563-1,16257 \mathrm{x}\left(\mathrm{R}^{2}=0,95\right)$.

$\mathrm{P}^{* *}(=0,058), \mathrm{Y}=856,339-1,61307 \mathrm{x}\left(\mathrm{R}^{2}=0,43\right)$.

$\mathrm{P} * * *(=0,004), \mathrm{Y}=656,487-1,51314 \mathrm{x}\left(\mathrm{R}^{2}=0,96\right)$.

$\mathrm{P} * * * *(=0,006), \mathrm{Y}=1,21768+0,0100464 \mathrm{x}-0,000146484 \mathrm{x}^{2}\left(\mathrm{R}^{2}=0,97\right)$

Tabela 6 - Coeficiente de digestibilidade da matéria seca, nitrogênio, extrato etéreo em pintos de corte de 1 a 7 dias de idade alimentados com rações com diversos níveis de milho pré-gelatinizado

\begin{tabular}{|c|c|c|c|c|c|c|}
\hline & \multicolumn{4}{|c|}{ Nível de substituição (\%) } & \multirow[b]{2}{*}{ CV (\%) } & \multirow[b]{2}{*}{$\mathrm{P}$} \\
\hline & 0 & 20 & 40 & 60 & & \\
\hline \multicolumn{7}{|c|}{1 a 7 dias de idade } \\
\hline Matéria seca (\%) & 78,48 & 73,43 & 71,07 & 80,84 & 7,03 & 0,039 \\
\hline Nitrogênio (\%) & 68,71 & 73,93 & 67,90 & 59,95 & 12,10 & $>0,05$ \\
\hline Extrato etéreo (\%) & 84,53 & 89,67 & 82,11 & 84,79 & 3,71 & $>0,05$ \\
\hline Matéria seca (\%)* & 87,65 & 89,17 & 88,87 & 89,43 & 1,28 & 0,036 \\
\hline Nitrogênio $(\%)^{* *}$ & 81,71 & 80,23 & 82,43 & 86,86 & 2,11 & $<0,001$ \\
\hline Extrato etéreo $(\%)^{* * *}$ & 91,22 & 92,18 & 92,87 & 93,41 & 1,03 & $<0,001$ \\
\hline
\end{tabular}

$\mathrm{Y}=78,8842-0,528026 \mathrm{x}+0,00921310 \mathrm{x}^{2}\left(\mathrm{R}^{2}=0,92\right)$.

$\mathrm{P}^{*}(=0,036), \mathrm{Y}=88,0301+0,0251716 \mathrm{x}\left(\mathrm{R}^{2}=0,69\right)$.

$\mathrm{P} * *(=0,000), \mathrm{Y}=80,1620+0,0882734 \mathrm{x}\left(\mathrm{R}^{2}=0,64\right)$

$\mathrm{P} * * *(=0,001), \mathrm{Y}=91,3368+0,0363235 \times\left(\mathrm{R}^{2}=0,98\right)$.

de substituição do milho por milho pré-gelatinizado, ponto de pior conversão alimentar. Para conversão alimentar, Fisher et al. (2002) observaram efeito significativo da substituição nos períodos dos 7 aos 14 dias e dos 28 aos 35 dias de idade.

Os níveis de substituição do milho tiveram efeito linear positivo nos coeficientes de digestibilidade (Tabela 6) da matéria seca, do nitrogênio e do extrato etéreo. O processamento por extrusão melhorou o coeficiente de digestibilidade do amido do milho e do sorgo. As atividades das enzimas maltase do conteúdo do jejuno e íleo e amilase do conteúdo do jejuno foram influenciadas pelo processamento a calor dos cereais e foram maiores para as fontes extrusadas (Otutumi et al., 2005).

Hongtrakul et al. (1998) afirmaram que a formação de beta-amilase e amilopectina cristalizada durante o processo de extrusão em fontes de carboidratos pode diminuir a habilidade das enzimas amilases na ruptura das ligações do amido, levando a menor conversão do amido em carboidratos solúveis.

O milho pré-gelatinizado não piorou o desempenho de pintos de corte de 1 a 7 dias de idade. Os níveis de $20 \%$ e $40 \%$ de inclusão de milho pré-gelatinizado na dieta proporcionaram desempenho similar ao obtido com a dieta à base de milho. Freitas et al. (2005) verificaram que, com a utilização de milho processado (vapor e temperatura de 63 a $105^{\circ} \mathrm{C}$ ), houve piora do desempenho de frangos na fase pré-inicial, com maior consumo e pior conversão alimentar, mesmo quando a energia metabolizável aumentou cerca de $100 \mathrm{kcal}$ com o processamento. Plavnik \& Sklan (1995) afirmaram que, mesmo com o aumento que o processo de extrusão ou expansão provocaram nos valores de energia metabolizável do milho, o desempenho das aves não foi alterado. 
Na fase de 8 a 21 dias de idade, o alimento teve influência negativa principalmente sobre a conversão alimentar, que foi pior no nível de $34,22 \%$, portanto, a inclusão do milho pré-gelatinizado não é interessante para essa fase.

\section{Conclusões}

O milho pré-gelatinizado é uma boa alternativa como alimento energético para pintos de corte na primeira semana de vida, no entanto, apesar dos bons índices de digestibilidade, não favorece o desempenho na fase inicial.

\section{Agradecimentos}

Os autores agradecem à GEM Alimentos e ao CNPq, pela disponibilização de recursos financeiros ao projeto.

\section{Literatura Citada}

ALBINO, L.F.T. Sistemas de avaliação nutricional de alimentos e suas aplicações na formulação de rações para frangos de corte. 1991. 134f. Tese (Doutorado em Zootecnia) Universidade Federal de Viçosa, Viçosa, MG, 1991.

BRITO, A.B.; STRINGHINI, J.H.; CRUZ, C.P. et al. Efeito do gérmen integral de milho sobre o desempenho e rendimento de carcaça de frangos de corte. Arquivo Brasileiro de Medicina Veterinária e Zootecnia, v.57, n.2, p.241-249, 2005.

CAFÉ, M.B. Estudo do valor nutricional da soja integral processada para aves. 1993. 97f. Dissertação (Mestrado em Zootecnia) - Faculdade de Ciências Agrárias e Veterinárias/ Universidade Estadual Paulista, Jaboticabal, 1993.

CASTRO, A.G.M. Qualidade de pintos de um dia e importância do manejo no desempenho de frangos de corte. In: SIMPÓSIO GOIANO DE AVICUlturA, 2., 1996, Goiânia. Anais... Goiânia: Associação Goiana de Avicultura/UFG, 1996. p.67-70.

DALE, N. Efeitos da qualidade no valor nutritivo do milho. In: CONFERÊNCIA APINCO 1994 DE CIÊNCIA E TECNOLOGIA AVÍCOLAS, Santos, 1994. Anais... Campinas: Fundação Apinco de Ciência e Tecnologia Avícolas, 1994. p.67-72.

FASUYI, A.O. Maize-sorghum based brewery by-product as an energy substitute in broiler starter: effect on performance, carcass characteristics, organs and muscle growth. International Journal of Poultry Science, v.4, n.5, p.334-338, 2005.

FISHER, G.; MAIER, J.C.; RUTZ, F. et al. Desempenho de frangos de corte alimentados com dietas à base de milho e farelo de soja, com ou sem adição de enzimas. Revista Brasileira de Zootecnia, v.31, n.1, p.402-410, 2002.

FOOD OREGON STATE. [2006]. Disponível em: <http:// food.oregonstate.edu/starch/>. Acesso em: 10/2/2006.

FREITAS, E.R.; SAKOMURA, N.K.; NEME, R. et al. Valor nutricional do milho termicamente processado, usado na ração pré-inicial para frangos de corte. Arquivo Brasileiro de Medicina Veterinária e Zootecnia, v.57, n.4, p.510-517, 2005.

HONGTRAKUL, K; GOODBAND, R.D.; BEHNKE, K.C. et al. The effect of extrusion processing of carbohydrate sources on weanling pig performance. Journal of Animal Science, v.76, n.12, p.3034-3042, 1998.

JORGE NETO, G. Soja integral na alimentação animal. In: SEMINÁRIO DE SUÍNOS GUABI, 1993, Lindóia. Apostilas... Lindóia, 1993. p.99-106.

JORGE NETO, G. Soja integral na alimentação de aves e suínos. Avicultura e Suinocultura Industrial, v.82, n.988, p.4-15, 1992.

JOY, M.T.; DePETERS, E.J.; GADEL, J.G. et al. Effect of corn processing on the site and extent of digestion in lactating cows. Journal of Dairy Science, v.80, p.2087-2097, 1997.

LARBIER, M.; LECLERQ, B. Nutrition and feeding of poultry. Nottingham: University Press, 1994. 350p.

LIMA, G.J.M.M. Milho e subproduto na alimentação animal. In: SIMPÓSIO SOBRE INGREDIENTES NA ALIMENTAÇÃO ANIMAL, 1., 2001, Campinas. Anais... Campinas: Colégio Brasileiro de Nutrição Animal, 2001. p.13-32.

MATTERSON, L.D.; POTTER, L.M.; STUTZ, M.W. et al. The metabolizable energy of feeds ingredients for chickens. Connecticut: University of Connecticut, 1965. 11p.

MOREIRA, I.; ROSTAGNO, H.S., COELHO, D.T. Determinação dos coeficientes de digestibilidade, valores energéticos e índices de controle de qualidade do milho e soja integral processados a calor. Revista Brasileira de Zootecnia, v.23, p.916-929, 1994.

MOREIRA, I.; OLIVEIRA, G.C.; FURLAN, A.C. et al. Utilização da farinha pré-gelatinizada de milho na alimentação de leitões na fase de creche, digestibilidade e desempenho. Revista Brasileira de Zootecnia, v.30, n.2, p.440-448, 2001.

OLIVEIRA, R.P.; FURLAN, A.C.; MOREIRA, I. et al. Valor nutritivo e desempenho de leitões alimentados com rações contendo silagem de grãos úmidos de milho. Revista Brasileira de Zootecnia, v.33, n.1, p.146-156, 2004

OTUTUMI, L.K.; FURLAN, A.C.; SCAPINELLO, C. et al. Digestibilidade e atividade enzimática de coelhos em crescimento alimentados com diferentes fontes de amido processadas ou não por extrusão. Revista Brasileira de Zootecnia, v.34, n.2, p.557-567, 2005.

PLAVNIK, I.; SKLAN, D. Nutritional effects of expansion and short time extrusion on feeds for broilers. Animal Feed Science and Technology, v.55, n.3-4, p.247-251, 1995.

PENZ JR., A.M; VIEIRA, S.L. Nutrição na primeira semana. In: SIMPÓSIO INTERNACIONAL SOBRE MANEJO DE PINTOS DE CORTE, 1998, Campinas. Anais... Campinas: Fundação Apinco de Ciência e Tecnologia Avícolas, 1998. p.121-139.

RODRIGUES, P.B.; ROSTAGNO, H.S.; ALBINO, L.F.T. et al. Valores energéticos do milheto, do milho e subprodutos do milho, determinados com frangos de corte e galos adultos. Revista Brasileira de Zootecnia, v.30, n.6, p.1767-1778, 2001 (supl.)

ROSTAGNO, H.S.; ALBINO, L.F.T.; DONZELE, J.L. et al. Tabelas brasileiras para aves e suínos: composição de alimentos e exigências nutricionais. Viçosa, MG: Editora UFV, 2000. 61p.

SILVA, D.J.; QUEIROZ, A.C. Análise de alimentos (métodos químicos e biológicos). 2.ed. Viçosa, MG: Editora UFV, 2002. $208 p$.

TOLEDO, R.S.; VARGAS JR., J.G.; ALBINO, L.F.T. et al. Aspectos práticos da nutrição pós-eclosão: níveis nutricionais utilizados, tipos de ingredientes e granulometria da dieta. In: CONFERÊNCIA APINCO DE CIÊNCIA E TECNOLOGIA AVÍCOLAS, 2001, Campinas. Anais... Campinas: Fundação Apinco de Ciência e Tecnologia Avícolas, 2001. p.153-167.

UNIVERSIDADE FEDERAL DE VIÇOSA - UFV. Sistema de análise estatísticas e genéticas - SAEG. Versão 9.0. Viçosa, MG: 2000. (CD-ROM). 